\title{
Alterações no Sistema de Fibras Elásticas da Fáscia Endopélvica de Paciente Jovem com Prolapso Uterino
}

\author{
Elastic Fiber System Changes in the Endopelvic Fascia of a Young Patient with \\ Uterine Prolapse - A Case Report
}

\begin{abstract}
Consuelo Junqueira Rodrigues ${ }^{1}$, Henrique Oscar Fagundes Neto ${ }^{1}$, Marcos Lucon ${ }^{1}$, Renato Lupinacci ${ }^{1}$, Domingos Petti ${ }^{2}$, Laudelino de Oliveira Ramos ${ }^{2}$, Aldo Junqueira Rodrigues $\mathrm{Jr}^{1}$
\end{abstract}

\begin{abstract}
RESUM0
É apresentado um caso de prolapso do útero de $2^{\circ}$ grau em paciente de 18 anos, virgem. Durante o ato cirúrgico corretivo (cirurgia de Gillian) foram recolhidas amostras dos ligamentos e fáscias para avaliação do sistema de fibras elásticas. Foram demonstradas alterações estruturais nas fibras elásticas semelhantes às que ocorrem no envelhecimento, o que promove o enfraquecimento do tecido conjuntivo induzindo ao defeito de suporte do assoalho pélvico.
\end{abstract}

PALAVRAS-CHAVE: Prolapso uterino. Fáscia pélvica. Matriz extracelular.

\section{Introdução}

A manutenção das estruturas pélvicas em sua posição anatômica normal depende da integridade funcional do diafragma pélvico. Este apresenta dois componentes: um muscular, representado pelo músculo levantador do ânus, e outro conjuntivo, representado pela fáscia endopélvica ${ }^{1}$. Na mulher o componente muscular participa ativamente da oclusão do hiato urogenital, o que lhe confere importante função no mecanismo de estática das estruturas pélvicas. É fácil interpretar que eventual redução do tônus muscular do músculo elevador do ânus seja decorrente de trauma ginecológico, atrofia senil ou nos casos de espinha bífida, gere dilatação exagerada do hiato urogenital e prolapso urogenital ${ }^{2,3}$. Neste sentido, entra em ação um complexo sistema ligamentar da fáscia endopélvica, que interliga as estruturas à parede pélvica, auxiliando na estática das mesmas.

Entretanto, merece destaque que a etiologia do prolapso urogenital é multifatorial, estando relacionada à idade, à raça branca, à obesidade, ao trabalho físico, à pressão intra-abdominal aumen-

Departamentos de Cirurgia $^{1}$ e de Obstetrícia e Ginecologia ${ }^{2}$, Faculdade de Medicina, Universidade de São Paulo.

Correspondência:

Consuelo Junqueira Rodrigues

Faculdade de Medicina USP

Av. Dr. Arnaldo, 455, Sala 1304

01246-903 - São Paulo - SP tada, às doenças do tecido conjuntivo, ao tabagismo, à deficiência de estrógeno, à histerectomia prévia, às neuropatias e à multiparidade ${ }^{1-4}$.

Esta característica etiológica multifatorial acena para uma outra questão: é possivel qualificar ou ainda quantificar o papel do componente muscular e conjuntivo isoladamente? As alterações da matriz extracelular alteram o sinergismo do binômio músculo-conjuntivo e comprometem o funcionamento do assoalho pélvico?

Em face destes dados, é necessário estabelecer com clareza o papel da fraqueza do tecido conjuntivo na disfunção do assoalho pélvico, para que possamos diferenciar os casos clínicos e indicar tratamento individualizado.

No presente trabalho, relatamos um caso de prolapso uterino grau II em paciente jovem, nuligesta e virgem, que apresentou recidiva após correção cirúrgica. O estudo histológico dos ligamentos pélvicos e da fáscia muscular mostrou alterações estruturais, que contra-indicaram a reintervenção cirúrgica, em vista da certeza da recorrência.

\section{Relato do Caso}

Paciente, W.S.O, 18 anos, negra, virgem, apresentou menarca aos 12 anos. A paciente estava em bom estado geral com ciclos 4/28 em quan- 
tidade normal, queixando-se de dismenorréia e corrimento amarelado, sem odor, não-pruriginoso, em pequena quantidade. Ao exame físico a membrana himenal estava integra, perfurada, anular; visualizava-se colo uterino com ectopia cervical; à manobra de esforço o colo uterino exteriorizavase através da membrana himenal por aproximadamente 2 a $3 \mathrm{~cm}$.

Os exames de imagem realizados, raios $\mathrm{X}$ e ressonância magnética (RM) de coluna, mostraram espinha bífida em S1. A avaliação neurológica não revelou sinais clínicos de espinha bífida. A eletromiografia, até nível de $\mathrm{S} 1$, e o estudo neurofisiológico dos nervos pudendos não mostraram alterações ou anormalidades.

Com o diagnóstico de prolapso uterino grau II, a paciente foi submetida à correção cirúrgica, tendo sido realizada a cirurgia de Gillian. Neste ato cirúrgico foram colhidas biópsias dos ligamentos e fáscias musculares para avaliação histológica. As biópsias foram submetidas a métodos de coloração seletivos para evidenciação do sistema de fibras elásticas: Verhoeff para evidenciar fibras elásticas maduras, Weigert para fibras elauninicas e maduras e Weigert-oxona para fibras oxitalânicas, elaunínicas e maduras. Após dois meses de pós-operatório a paciente apresentou recidiva do prolapso uterino grau I, evidenciado em exame clínico e de RM. Proposto o uso de pessário, a paciente segue em acompanhamento ambulatorial.

\section{Resultados}

Análise histopatológica revelou ligamento redondo mostrando feixes de fibras musculares lisas entremeadas por tecido conjuntivo denso. Numerosas fibras elásticas espessas, tortuosas e desorganizadas envolvem o músculo liso. No tecido conjuntivo, observam-se numerosas fibras elásticas espessas, fragmentadas e tortuosas e dispostas em agrupamentos; estas fibras correspondem às fibras maduras e elaunínicas responsáveis pela elasticidade do tecido. Não foram observadas fibras elásticas mais finas, que correspondem às fibras oxitalânicas, que auxiliam na resistência dos tecidos (Figura 1). O ligamento útero-sacro mostrou feixes de músculo liso envoltos por fibras elásticas espessas, longas e por vezes tortuosas, dispostas em agrupamentos (Figura 2). As fáscias de Scarpa e de Camper mostraram tecido conjuntivo denso com fibras elásticas longas e espessas, distribuídas homogeneamente. Presença de raras fibras elásticas oxitalânicas. A fáscia dos músculos oblíquos in- terno e externo mostrou tecido conjuntivo com fibras elásticas espessas, fragmentadas e agrupadas. Presença de raras fibras oxitalânicas.

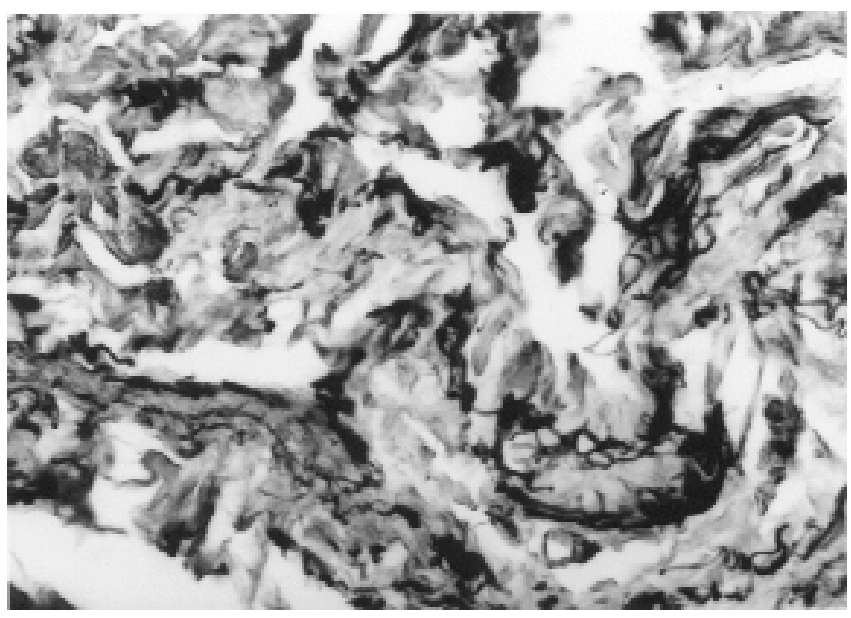

Figura 1 - Ligamento redondo. Fibras elásticas espessas, fragmentadas e agrupadas em meio a tecido conjuntivo denso. Weigert-oxona 300X.

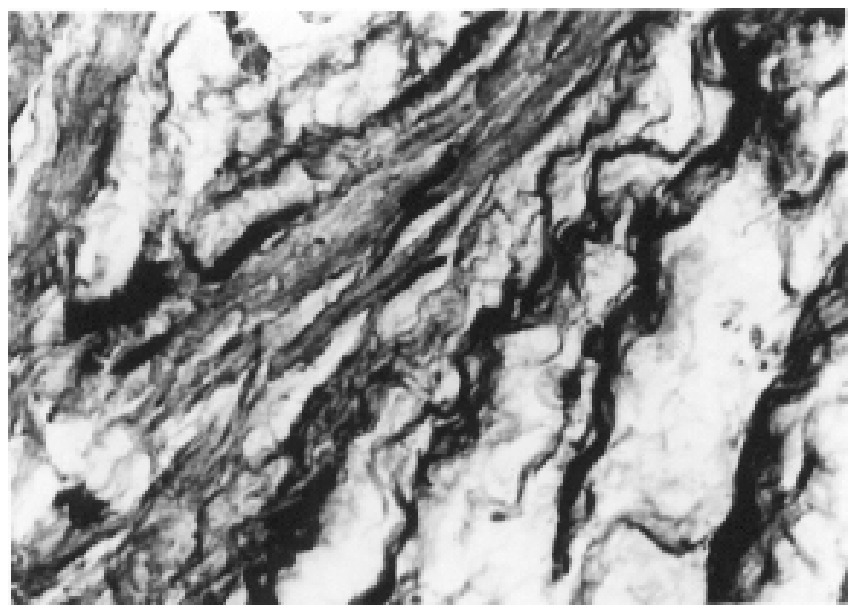

Figura 2 - Ligamento útero-sacro. Grande quantidade de fibras elásticas espessas e por vezes tortuosas envolvendo feixes de músculo liso. Verhoeff $600 \mathrm{X}$.

\section{Discussão}

O prolapso uterino geralmente está associado à multiparidade em mulheres menopausadas. Este diagnóstico em neonatos e mulheres jovens e/ou nuliparas parece ser decorrente de defeito da inervação do assoalho pélvico que acompanha as mielodisplasias, anomalias da segmentação lombo-sacral ou trauma que promovem a paralisia muscular favorecendo a protusão de vísceras abdominais e estruturas pélvicas ${ }^{2,3}$. 
A fáscia endopélvica é uma malha de fibras colágenas e elásticas, por onde correm vasos e nervos. A presença de alterações estruturais do tecido conjuntivo da fáscia contribui para o enfraquecimento dos ligamentos, favorecendo a protusão de vísceras pélvicas. Pouco tem sido investigado a respeito de alterações do tecido conjuntivo da fáscia endopélvica nestes casos. Só recentemente, considerou-se a fraqueza do tecido conjuntivo como um dos fatores colaboradores do prolapso uterino ${ }^{2,4,5}$.

Em relação ao componente de colágeno, estudos referem redução da celularidade ${ }^{5}$ e da quantidade de colágeno ${ }^{4}$, maior produção de colágeno tipo $\mathrm{III}^{2}$, bem como alterações inerentes do tecido conjuntivo, como ocorre na síndrome de Ehlers-Danlos e de Marfan ${ }^{1-3}$. Entretanto, raros são os relatos que se referem às alterações do componente elástico da fáscia endopélvica. Demonstrou-se a fragmentação e redução da quantidade de fibras elásticas na parede vaginal de pacientes com cistocele ${ }^{6}$.

A elasticidade, e portanto a complacência dos tecidos é dada pelo sistema de fibras elásticas, que está constituído por arcabouço microfibrilar que contém elastina, as fibras maduras e as elaunínicas, responsáveis pela elasticidade, e por fibras oxitalânicas, que contêm apenas microfibrilas, sendo responsáveis pela resistência. Estas fibras estão interligadas pelo fenômeno da elastogênese, no qual primeiro são lançadas as microfibrilas no meio extracelular, que recebem deposição de elastina. Dependendo da função do tecido, elasticidade ou resistência, varia a quantidade e o tipo de fibra elástica. Além disso, alterações estruturais e arquiteturais do sistema de fibras elásticas promovem redução da elasticidade e conseqüente enfraquecimento dos tecidos, como ocorre com o envelhecimento da fáscia transversal, que favorece o aparecimento de hérnia inguinal direta $^{7}$, e da fáscia dos músculos esqueléticos, promovendo redução da complacência muscular ${ }^{8}$.

Em nosso estudo demonstramos alterações estruturais das fibras elásticas, ou seja, espessamento, tortuosidade e fragmentação, bem como desarranjo arquitetural. Estas alterações são semelhantes àquelas encontradas no envelhecimento do tecido conjuntivo. Estas alterações das fibras elásticas, que podem ser decorrentes de defeito da elastogênese ou aumento da atividade elastolítica, tornam a fáscia endopélvica menos complacente e com frouxidão, o que parece ter favorecido o aparecimento de prolapso uterino nesta paciente.

\section{SUMMARY}

A case report of a young virgin patient with a seconddegree uterine prolapse is presented. During the corrective surgery (Gillian surgery) samples of the ligaments and the pelvic fascia were obtained to evaluate the elastic fiber system. There were structural changes of the elastic fibers similar to ageing process, which promotes connective tissue weakness inducing a pelvic support defect.

KEY WORDS: Uterine prolapse. Pelvic fascia. Extracellular matrix.

\section{Referências}

1. DeLancey JOL. Anatomy and biomechanics of genital prolapse. Clin Obstet Gynecol 1993; 36:897-909.

2. Norton PA. Pelvic floor disorders: the role of fascia and ligaments. Clin Obstet Gynecol 1993; 36:92638.

3. Loret de Mola JR, Carpenter SE. Management of genital prolapse in neonates and young women. Obstet Gynecol Surv 1996; 51:253-60.

4. Jackson SR, Avery NC, Tarlton JF, Eckford SD, Abrams P, Bailey AJ. Changes in metabolism of collagen in genitourinary prolapse. Lancet 1996; 347:1658-61.

5. Mäkinen J, Söderström K, Kiiholma P, Hirvonen T. Histological changes in the vaginal connective tissue of patients with and without uterine prolapse. Arch Gynecol 1986; 239:17-20.

6. el-Kholi GY, Mina SN. Elastic tissue of the vagina in genital prolapse. A morphological study. J Egypt Med Assoc 1975; 58:196-204.

7. Rodrigues Junior AJ, de Tolosa EM, de Carvalho CA. Electron microscopic study on the elastic and elastic related fibers in the human fascia transversalis at different ages. Gegenbaurs Morphol Jahrb 1990; 136:645-52.

8. Rodrigues CJ, Rodrigues Junior AJ. A comparative study of aging of the elastic fiber system of the diaphragm and the rectus abdominis muscles in rats. Braz $\mathrm{J}$ Med Biol Res. In press. 